\title{
Appendix B: Questionnaire for Primary Data
}

Table B1: Brief Profile of the Respondents.

1 Name of the respondent

2 Gender (male/female)

3 Age in years

4 Academic qualifications

5 Present occupation

6 Present designation

7 Institution where respondent is working, if required

8 Communication address

9 Contact number with E-mail address

10 Category of Respondent Please put a tick mark $(\checkmark)$

Chartered accountant in practice Students pursuing CA final course 
This is a self-administered questionnaire designed for pursuing our self-financed research work. The purpose of the study is absolutely academic. None of the information/perceptions that you communicate in this questionnaire will be disclosed to any other party using your personal name, but these information/perception may be incorporated into the research work.

SA: Strongly Agree, A: Agree, N: Neutral, D: Disagree, SD: Strongly Disagree 
Table B2: Chapter 5 Questionnaire.

Please put a tick mark $(\boldsymbol{V})$ in the appropriate

box

No.

Statements

SA

A

$\mathrm{D}$

Parameter 1: Quality Control of Audit Procedure

$1 \quad$ Quality control policies are properly designed by CEOs of most of the accounting firms in India.

$2 \quad$ All the partners and employees of the firm should have required integrity, objectivity and competence for ethical completion of audit procedure.

3 Most of the accounting firms in India provide education and training to new members of the firm to make them conversant with the quality control procedure.

$4 \quad$ Every accounting firm should establish stringent policies of punishment if quality control policies are not performed by members of the firm.

5 Information provided by the engagement partner on the client profile is not sufficient for the firm to understand threats to independence after accepting audit engagement.

6 A long auditor relationship with the audit client reduces audit quality.

Credibility and integrity of the client should be mandatorily checked by the audit firm before accepting engagement as per the requirements of SQC1. 
No.

8

\section{Statements}

The maximum period of association between an engagement partner and their audit client (seven years) is justified.

Engagement partners before accepting the engagement should verify that all the members of the engagement team are formally trained and competent to take up audit responsibilities.

Involvement of another senior partner of the accounting firm in the engagement team to review overall audit strategy enhances the quality of audit.

If the engagement team appoints an expert, the engagement partner should satisfy himself with the competence and integrity of the expert appointed to maintain quality of audit.

2 The internal quality control system and their actual compliance of the accounting firm should be constantly monitored by the Council of the ICAI.

In most audit firms, the competence and ethical requirements of the engagement team members are not thoroughly investigated. Few accounting firms in India appoint an engagement quality control reviewer (EQCR).

The independence of the EQCR should be thoroughly checked by the accounting firm before their appointment. 
Appointing firms have a proper system of resolving differences of opinion between the EQCR and the engagement partner. properly documented.

18 Engagement documentation kept for at least 10 years as per SQC1 is sufficient for an accounting firm.

19 If any allegation is received against any member or employees of noncompliance with professional or ethical standards, it should be resolved within the quality control framework of the firm.

\section{Parameter 2: Overall Objectives of an Independent Auditor}

In the case of continuous audit engagement, the statutory auditor should also design and perform his audit procedure with professional skepticism.

In recent auditing failures, statutory auditors failed to exercise sufficient professional skepticism to detect fraud and material misstatement.

Requirements of all standards on auditing (SAs) are not properly complied with for conducting audits of most Indian companies.

SAs are sufficient and understandable to fulfil all the responsibilities of statutory auditors.

24 The time allotted for undertaking a substantive audit procedure to ensure the reliability of financial statements is not adequate.

The costs incurred for a substantive audit procedure to ensure reliability of financial statements is not adequate. 
26 The fee structure of the statutory auditors should be revised so that they can undertake a substantive audit procedure.

27 The limit audit of 30 public limited companies at a time should be reduced to give more time to each engagement partner, resulting in improvement of their quality.

28 The time allowed to audit financial statements should be increased for some selected class of company which would allow the auditors for more detailed verification of accounting records.

Conducting audit periodically may reduce audit burden at the end of the year and will improve audit quality.

\section{Parameter 3: Audit Engagement}

If the statutory auditors have restricted access to all information from the client, they should not accept the engagement.

31 Statutory auditors should not accept audit engagement if any of the preconditions for accepting audit engagement are not met.

32 If the format of the audit report as per laws and regulations applicable to the company is different from the requirements of the SA, the auditor should separately mention this fact in the audit report to mitigate misunderstanding of any users. 


\section{Parameter 4: Internal Control System and Internal Auditors}

The internal control system should be mandatorily checked in detail to obtain reasonable assurance as to the internal control of the reporting entity and designing audit procedure.

35 Excessive reliance placed on internal auditors' work does not reduce the responsibility of statutory auditors to maintain audit quality.

36 The technical competence and integrity of internal auditors should be tested by the statutory auditors.

37 The audit committee should take up more responsibility to strengthen communication between internal and external auditors.

The risk of material misstatement in accounting records assessed by internal auditors should be thoroughly checked by the external auditors.

The standards governing internal audit operations issued by the ICAI are not properly enforced.

\section{Parameter 5: Audit Planning}

Involvement of all members of the engagement team in the planning process would increase their effectiveness.

41 The auditor should possess the necessary independence and competence to develop audit plans. 
42 The engagement team members should investigate the client's ethical requirements in the subsequent audit engagements to update their audit plans.

43 In the audit plan, more resources and a greater number of engagement team members should be allocated to high-risk areas.

44 Before planning the nature, timing and extent of an audit, the risk of material misstatement should be assessed.

45 The auditor maintains a memorandum of the audit strategy, complete audit programme, audit completion checklist, etc. as a part of the plan process.

46 The involvement of another audit partner to review the validity of the audit strategy can improve the quality of audit.

\section{Parameter 6: Audit Evidence}

47 Persuasive instead of conclusive audit evidences may reduce the quality of audit.

$48 \quad$ The statutory auditors should design the audit procedure appropriately for collecting sufficient appropriate audit evidences. 
Verification of assets (e.g. fixed assets, inventory) provides reasonable audit evidence of their existence.

Verification of the internal control system through direct observation of control will ensure the quality of audit.

Formal written inquiries are more reliable audit evidences than informal oral inquiries.

Confirmations received from external parties may not always be reliable.

Excessive reliance on management experts may reduce audit quality.

One or more experts should be included in the engagement team to verify the reports given by the management valuer.

The engagement partner should collect sufficient appropriate evidence as to the competence, independence and integrity of the management expert.

Reliance on management's system for physical verification of inventory reduces the quality of audit.

After receiving a physical count of inventory from the management, statutory auditors should physically inspect the same to some extent.

Physical counting of inventory should be done by the statutory auditors without prior announcement in order to check the accuracy of the management report.

59 A more stringent audit procedure should be applied to receive third party confirmation when any inventory is held by them as collateral. 


$$
\text { No. }
$$

Statements

\section{SA}

A

$\mathrm{D}$

Parameter 7: Audit Sampling

60 Audit based on 'audit sampling' reduces audit quality.

61 If the verification based on audit sampling does not help auditors

to form a reasonable conclusion, they should change the nature, timing and scope of the audit procedure to gather more reliable samples.

62 Statutory auditors should possess adequate knowledge in statistical application to design an appropriate sample.

63 The auditor should try to keep their risk tolerance at its minimum, thereby selecting a larger sample.

\section{Parameter 8: External Party Confirmation}

64 The confirmation request should be scientifically designed to obtain reliable confirmation.

65 If the company is in a legal dispute with the confirming party, the auditor should seek an alternative method for getting confirmation.

66 The auditor needs external confirmation mainly for the accounts receivable and accounts payable balance. 


\section{Parameter 9: Using the Work of an Expert}

67 The statutory auditor's responsibility is not reduced by the auditor's use of the work of an auditor's expert with regard to valuation of fixed and intangible assets, contracts and other issues.

68 The auditor shall evaluate whether the auditor's expert has the necessary competence, capabilities and objectivity for the auditor's purposes.

\section{Parameter 10: Accounting Estimates}

69 Accounting estimates hinder auditors from drawing conclusive evidence on the financial statement.

70 In the initial audit engagement, it is difficult for the statutory auditors to identify management bias in using accounting estimates.

71 Statutory auditors should inquire as to the management justification for using an accounting estimate for certain classes of transaction.

72 The auditors should not completely rely on the expert's certificate on accounting estimates.

\section{Parameter 11: Audit Documentation}

73 Audit documents maintained properly are helpful to the accounting firm in case of any further queries.

74 Regulatory requirements of the audit procedure should be properly documented under the audit file. 


\begin{tabular}{llllllll}
\cline { 2 - 6 } No. & Statements & SA & A & N & D & SD
\end{tabular}

$75 \quad$ Audit documentation should provide auditors with professional skepticism in accordance with SAs.

76 The basis for auditors' conclusions on the authenticity of a document should be properly documented.

77 If statutory auditors take additional audit procedures apart from the requirements of SAs, that should be properly documented.

\section{Parameter 12: Audit Report}

78 The audit report should contain compliance with appropriate auditing standards.

79 If the statutory auditors fail to comply with the requirements of certain SAs it should be properly stated in the audit report.

80 The audit report should also include the future viability of the company operation.

Parameter 13: General Issues Governing Audit Quality

81 Verifying compliance with all the relevant regulatory requirements by the statutory auditors is not always possible. The current appointment procedure of statutory auditors gives management enough scope to influence auditors, resulting in reduction of audit quality. 
An independent statutory body should be entrusted with the duty of appointing statutory auditors to maintain audit quality.

Whistle blowers from the company may help statutory auditors to detect possible red flags of fraudulent activities.

Whistle blower policies under Clause 49 of the listing

requirement of the SEBI should be enforced effectively to improve audit quality.

Continuous learning programs initiated by the ICAI improve the competence of auditors and improve audit quality.

The outcome of the continuous learning programs of the ICAI should be evaluated on a periodical basis.

The present auditing system is not equipped to detect

systematically designed fraudulent techniques for material misstatement.

Consulting services provided by the accounting firms reduce the quality of their attestation engagements.

There should be complete diversification between accounting firms providing audit and consultancy services.

Auditing of propriety of transactions should come under the purview of financial audit.

Peer review of audit work cannot ensure audit quality effectively.

Cut-throat competition in the auditing profession sometimes forces audit firms to compromise their quality control policies. 
Table B2: (Continued)

$$
\text { box }
$$

No. Statements

SA

A

$\mathrm{D}$

SD

Dependent Variable

Quality Control Procedure for Statutory Financial Audit

95 The quality control procedure of statutory financial audit is satisfactory. 